\title{
Implementing the National Quality Standard in schools: leadership that motivates improvement initiatives through psychological ownership
}

\author{
Gillian Kirk ${ }^{1}$ (1) - Lennie Barblett ${ }^{1}$ (1)
}

Received: 3 September 2020 / Accepted: 15 March 2021 / Published online: 21 May 2021

(c) The Author(s) 2021

\begin{abstract}
From 2016, all Western Australian schools were mandated to implement the National Quality Standard (NQS) in Kindergarten through to Year 2. Over the first year of implementation, this mandate had varying degrees of success in adoption. This study examined four schools which were identified as having implemented the NQS. A qualitative methodology was employed to examine those factors that supported implementation. A key finding was the integral role played by distributed leadership in adopting new initiatives. Using Activity Theory to conceptualise the data, it was found that psychological ownership was a key factor in enabling distributed leadership. Ownership was enabled when community differences were acknowledged, and time was given for the NQS tool to be reassessed and reconfigured as one's own. Once staff had psychological ownership, they were more likely to support implementation of the NQS. This study has implications for leaders and those implementing the NQS or other initiatives in schools.
\end{abstract}

Keywords Quality early childhood · National Quality Standard · Psychological ownership · Distributed leadership

\section{Introduction}

In 2012, the National Quality Framework (NQF) was introduced to improve education and care in family and long day care centres, Preschools/Kindergartens, and outside school hours care. A key component of the NQF was the National Quality Standard (NQS) which outlined seven Quality Areas considered integral to the provision of quality education and care for children from birth to age five in children's services and older children in out of school care. The aims of the NQS are to assist

Gillian Kirk

g.kirk@ecu.edu.au

1 School of Education, Edith Cowan University, Joondalup, WA, Australia 
in the continuous improvement of practice to assure "the safety, health and wellbeing of children, a focus on achieving outcomes for children through high-quality educational programs and improve families' understanding of a quality service" (Australian Children's Education and Care Quality Authority [ACECQA], 2020).

In Western Australia (WA), the non-compulsory Kindergarten programmes (4-year-old children) are usually attached to a primary school and come under the leadership of the school principal. For this reason, in 2016, the Premier of WA requested permission from the Prime Minister to exclude WA Kindergartens from the national laws and regulations for the NQF and instead implement the Quality Areas of the NQS under the School Education Act 1999 (Minister for Education and Training 1999). Upon approval, under the direction of the Education Minister, Honourable Peter Collier, a revised model was developed by a cross-sectorial group representing public, Independent and Catholic school sectors. This group recommended not only Kindergartens implement the NQS, but also Pre-primary (Foundation), Year 1 and Year 2. In place of an external auditor, the school principal or a nominee would conduct the NQS audit to determine which Quality Areas were 'meeting' or 'working towards', a rating system unique to this approach (Barblett \& Kirk, 2018).

Schools were informed that the mandatory implementation of the NQS would take place in 2016. Prior to this time, the sectors provided professional learning to familiarise each school with the standards. As it transpired, the initial NQS professional learning originated as a one-off event, an occurrence which is in isolation from human agency. Effective change, however, cannot be approached as an event; it needs to be developed within a process that is dependent on collective agentic behaviours (Hall \& Hord, 2006). This process was acknowledged in an earlier paper on this current study that examined how four schools effectively implemented the NQS. This previous paper highlighted the role of distributed leadership in supporting the implementation of mandated reform and how distributed leadership is established over time (Barblett \& Kirk, 2018). In this current paper we argue that distributed leadership is effective as it enables the transference of psychological ownership, which is critical in the uptake and implementation of the NQS. Once psychological ownership was transferred from leaders to staff, each staff member began to see themselves as owning the outcome of improved practice in their school. Essentially, the position is taken that psychological ownership is necessary if sustainable change is to take effect. The third-generation activity theory (AT) as described by Engeström (1987) in his book, Learning by expanding, was utilised in this study to conceptualise the findings and to demonstrate how psychological ownership is integral to enduring change processes.

\section{Psychological ownership}

Avey, Wernsing, and Palanski (2012) purport that psychological ownership is defined as an individual's perception that the target or outcome (hereon in referred to as outcome) is their own. This perception can be held at both an individual and collective-level where individuals in a group feel the outcome is collectively theirs 
(Alok, 2014). Psychological ownership is a higher-order construct (Alok, 2014) comprising "self-efficacy, accountability, belongingness, and identity" (Avey et al., 2012, p. 24). Studies have identified psychological ownership as predictive of the individuals' attitudes, behaviours, and performance, largely due to these constructs (For example: Park, Song, \& Kim, 2013).

When individuals are self-efficacious, they believe they can succeed at certain tasks and are more confident in working with the outcome (Alok, 2014). With psychological ownership they feel more accountable for what happens to the outcome and feel a greater sense of belonging to the target or outcome (Avey et al., 2012). When the outcome becomes their own, it confirms their notion of identity within the organisation (Alok, 2014). Psychological ownership is also socially constructed, with power relations influencing how ownership manifests (Yip et al., 2014). Hence social contexts determine the extent and possibility for psychological ownership to develop.

\section{Leadership}

Change that necessitates action to achieve goals is what differentiates educational leadership from educational management. Educational management considers the functioning of a system, whereas educational leadership is centred on influencing others (Connolly, James, \& Fertig, 2017). Fullan (2014) acknowledges that a key task of educational leadership is to manage change, and in doing so, influence others as dual change agents.

Contemporary views of educational leadership align with distributed notions of power (Barblett \& Kirk, 2018) that are characterised by the open sharing of information, participant autonomy, and ethical decision making (Australian Public Service Commission, 2018). This view of leadership is represented by three interconnected key features: catalytic agency, reflective integrity and relational interdependence. Catalytic agency refers to the individual taking personal responsibility to act as a change agent; reflective integrity is the reflection on outcomes at both the individual and organisational level, and relational interdependence is when everyone recognises that to reach an outcome effectively, there needs to be mutual dependence (McDowall \& Murray, 2012).

To effect school change, educational leadership influences the collective belief that all staff within a school are part owners and share responsibility for the actions and outcomes (Man \& Farquharson, 2015). This is the point where educational leadership and psychological ownership interconnect. Without psychological ownership and the shared responsibility of decision making that it entails, catalytic agency would not eventuate (McDowall \& Murray, 2012). Recognising the role of psychological ownership in leadership extends beyond the leadership seen at the school level to the leadership exerted by the Department of Education (DoE) through their Office of Early Childhood Teaching and Learning (OECDL) team. The OECDL were charged with developing NQS tools in collaboration with other school sectors (i.e. Catholic and Independent) to teach staff about the NQS. It is only when participants in each of the levels (DoE, OECDL, school leaders and staff) gain their own 
sense of psychological ownership that they can support others in developing their ownership.

\section{Transformational leadership}

Transformational leadership is a person's ability to engage others for the purpose of building motivation (Stamopoulos \& Barblett, 2018). Bass and Riggio (2006) attribute this role to leaders who support staff in developing both commitment and a shared vision, thus fostering increased staff satisfaction in their positions. Such leaders consider staff achievement and growth and utilise coaching and mentoring methods to enable them to undertake more responsibility to become leaders themselves (Park et al., 2013).

Park et al. (2013) examined the mediating role of psychological ownership on transformational leadership and organisational citizenship behaviour. Two hundred and fourteen businesses from the Korean public sector were analysed using a structural equation and chi-square difference-based model to examine the mediating effect. They found a statistically significant relationship between transformational leadership and employees' psychological ownership and their organisational citizenship behaviour. From an educational perspective, Allen, Grigsby, and Peters, (2015) concurred, stating that this leadership style has potential to positively impact the organisational climate, with the sense of satisfaction improving both conditions and outcomes for both staff and students.

\section{Distributed leadership}

Distributed leadership models are considered more effective than top-down approaches (Stamopoulos \& Barblett, 2018). When leaders utilise the available talent within the organisation, they improve performance (Harris \& Hargreaves, 2013). This is achieved through flattened structures and by empowering employees with greater ownership of their work. Typically, employees are nominated to lead according to their expertise and are instrumental in the role of change and development. This structure is indicative of effective leadership that orchestrates a "lateral and vertical collaboration" that is instrumental in sustaining change and exceptional performance (Harris, 2013 p. 549). The research affirms that distributed leadership has the potential to positively influence individual and collective outcomes, but only under the conditions where it is approached and nurtured as a deliberate strategy for effective and sustainable change (Harris, 2013). The power relations within a distributed leadership model support the development of individual psychological ownership (Yip et al., 2014).

Harris (2013) identified distributed leadership as instrumental in schools' capacities to improve. She reported on Heck and Hallinger's (2010) study which examined 195 primary schools in one state over 4 years. This study found that a distributed approach had significant direct effects on change in the schools' "academic capacity and indirect effects on study growth rates in math" (p. 550). Other research found that distributed leadership was positively related to staff morale, which relates 
positively to student behaviour and student learning outcomes (Day, Sammons, Leithwood, Harris, \& Hopkins, 2009). However, the implementation of distributed leadership models is at times impeded by the better-known top-down approach of systems and internal school structures (Harris, 2003).

\section{Research design}

\section{Theoretical framework}

There are two key ideas embedded in the theoretical framework that underpin our study. The first is the third-generation Activity Theory (AT) perspective (Engeström, 1987, 2000a, 2001), and the second is the notion of psychological ownership discussed earlier. In this section, we will explain AT and how it relates to our study and situate psychological ownership within this theory.

Engeström (1987) presented the third-generation AT where the focus of analysis is on at least two interacting activity systems. Activity systems allows us to examine actions as "successive, momentary instantiations of a wider and more stable system of collective activity" and the impact these have on the participants and their development (Engeström, 2000a, p. 961). They are "driven by communal motives that are often difficult to articulate for individual participants. Activity systems are in constant movement and internally contradictory" (Engeström, 2000a, p. 960).

Engeström (2001) explains contradictions as "historically accumulated dynamic tensions within and between activity systems" (p. 137) and the solutions derived from these tensions drive transformations in activities and organisational change (Engeström, 1987). In this current study, the internal contradictions caused tensions as top down mandatory policy was demanded to be implemented in schools. In the professional learning the OECDL offered schools, they outlined solid reasons for the impetus for change for quality early childhood education. Yet the tensions still existed. Motivation is often required when searching for solutions to tensions, particularly when the tension has originated from a mandate.

We argue that the NQS is a form of motivation, however, it is one that is characterised by externally imposed constraints. Through psychological ownership the NQS is internalised and transforms from extrinsic to intrinsic motivation, facilitating a shift from 'having' to comply to 'wanting' to comply (Hennessey, Moran, Altringer, \& Amabile, 2015). Psychological ownership enables motivation through the enactment of "self-efficacy, accountability, belongingness, and identity" (Avey et al., 2012, p. 24), so, each participant becomes invested in change. Psychological ownership is transferred, and this transference occurs in each activity system as well as between activity systems during the process of implementing the NQS. The transference of psychological ownership is needed to motivate the resolve of tensions at each stage, from the OECDL team introducing the NQS to principals and key teachers, to staff in schools sharing it with other staff members. Moreover, we contend that the distributed leadership model supports psychological ownership when tension arises through the flattened structures and empowerment of staff (Harris, 2013; Yip et al., 2014). 
AT consists of six interrelated elements, these are: object, subject, community, tools and artefacts, division of labour and rules (Engeström, 2000a). Each of these is discussed here in reference to the context of the current research (see Fig. 1).

Engeström (2000a) refers to the object as the "raw material" that maintains the attention of the activity and contributes to how it is directed, moulded and transformed into outcomes with the help of mediating tools and signs. However, it exists independently, subjugating and transforming the subject's activity inferring an external influence over activity (Engeström, 1999). In this study, the object is the mandated NQS and the Quality Areas, and the activity refers to what people do to introduce or implement the NQS. For the adoption of this object to take place, it must itself transform from an extrinsic to intrinsic motivator. This departure from the external existence is made possible through psychological ownership. Psychological ownership will enable the adoption of the NQS through one's own volition and support the motivation to resolve tensions for the eventual instigation of desired change. Psychological ownership is transferred in the activity-how the participants shared or taught the NQS to others. Depending on the nature of the activity, the outcome is not merely the implementation of the NQS but the self-efficacy, accountability, belongingness, and identity (ownership) that is more likely to motivate the school community to implement the NQS in sustainable ways (Avey et al., 2012).

The second element is the subject. Subjects are the individuals (Engeström, 2000a, 2000b; Roth, 2004) in the activity system. In our context, the subjects are the staff involved in the activity who are developing psychological ownership in implementing the NQS. This includes the DoE and OECDL staff responsible for the policy decisions of the NQS, and all those staff involved in the implementation of the NQS in schools. Through the relations between subject (staff) and object (NQS) a transformation of individuals and their community takes place. Engeström (2000a) explains this change as being mediated by activity and tools; we suggest it is also mediated through psychological ownership that motivated staff to resolve tensions. Through psychological ownership, all staff are empowered to achieve the objective as they develop catalytic agency, reflective integrity and relational interdependence (McDowall \& Murray, 2012).

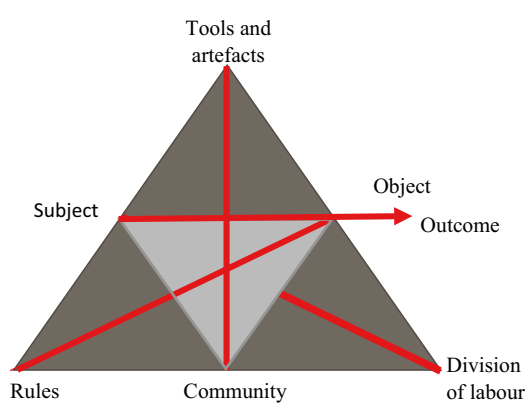

Engeström's theory

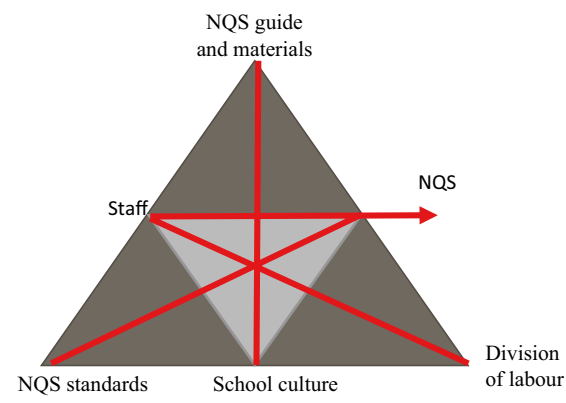

Theory applied to the study

Fig. 1 The triangle of activity and how the triangle applies to this current study 
The community comprises multiple individuals who share the same general object [NQS] and are distinct from other communities (Engeström, Engeström, $\&$ Suntio, 2002). In this study, each school is recognised as a unique cultural context, therefore each school could decide on their own implementation strategies. Hence, they were distinct from other school communities both before and after the activity (NQS implementation) takes place (see Fig. 2). Recognising this distinctness was a key component in leading the adoption of the NQS.

The tools and artefacts are the external and internal mediating instruments moulding the object (NQS) (Engeström et al., 2002). In this study the tools were the school revised NQS guide and supporting materials developed by the OECDL and school staff. Staff require self-efficacy in engaging with the NQS guide and accessing the materials, and through this engagement they develop accountability (Avey et al., 2012). The NQS tool also provided a means for reflective integrity as each Quality Area steps staff through a thoughtful and diverse examination of educational and developmental outcomes.

The element of division of labour considers the horizontal division of tasks between the individual or sub-groups of the community as well as the vertical division of power and status (Engeström et al., 2002). Finally, Engeström et al. (2002) states the element of rules are explicit and implicit regulations, norms and conventions that guide actions and interactions within the activity system. In this study, these relate to the standards made explicit in the NQS guide. When rules are adopted by the community, they govern the performance of the activity.

Gronn (2000) explains that "the potential for leadership is present in the flow of activities in which a set of organisation members find themselves enmeshed" (p. 331). It is proposed in this study that effective leadership is enabled through the transference of psychological ownership, as without this the flow of activities

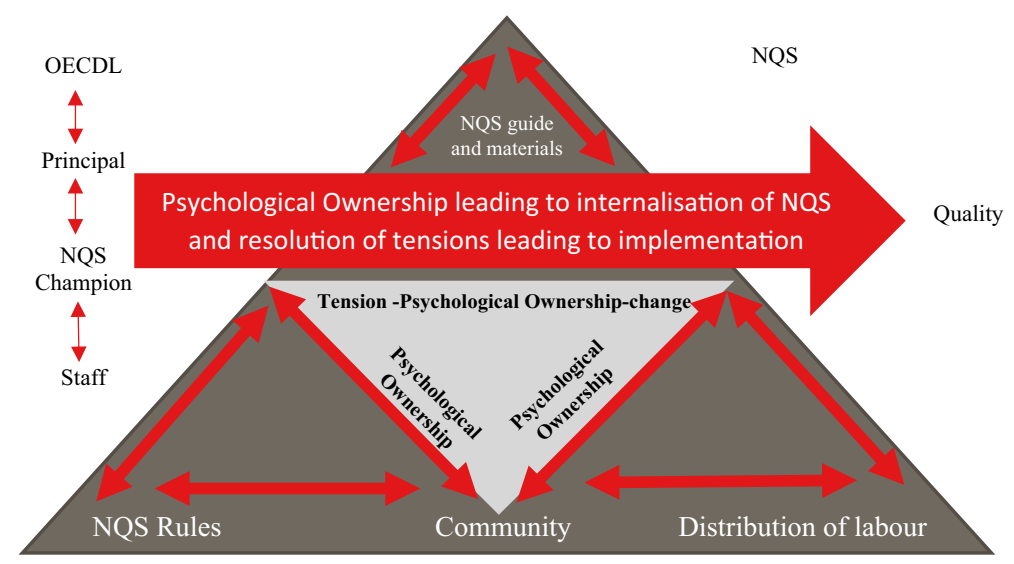

OECDL $\leftrightarrow$ Principal $\leftrightarrow$ NQS Champion $\leftrightarrow$ Staff

Fig. 2 A model of educational leadership for implementing the NQS in schools. Arrows denote the horizontal division of tasks between the individuals of the community as well as the vertical division of power and status (Engeström et al., 2002) 
will not be of value to the subjects and community and sustainable change will not be implemented.

\section{Method}

Qualitative research methods using a case study approach were utilised to describe the processes and strategies adopted by the schools to implement the NQS. A case study allows robust descriptions that are rich in detail and are "strong on reality" (Wellington, 2015, p. 174). The data were collected at the end of 2016, almost a full year after the NQS had been implemented in schools (Barblett \& Kirk, 2018).

The research question examined in this study and reported in this paper was:

- What aspects supported or impeded the implementation of the NQS?

\section{Participants}

Six DoE early childhood consultants from the OECDL and staff from four public primary schools participated in the study. Two of the schools were regional and the other two were metropolitan, and each was selected from schools known to be implementing the NQS. Fifty-two staff participated, including principals, deputy principals, teachers and assistants. The participation details are summarised in Table 1.

\section{Tools}

Semi-structured interviews were complemented by document analysis (i.e. business and operational plans; NQS improvement tools; teachers' planning documents and other NQS documents or materials) and observations of teachers at work. The semistructured interviews were conducted with all participants either individually, in pairs or in small groups, with each interview lasting approximately $1 \mathrm{~h}$.

University and Education Department ethics approvals were granted (Approval Number 13935). All participants were provided with an information letter describing the study and gave their consent to participate. Individual case studies were returned to the participants for comment and to ensure their perspectives were represented accurately. All participants were de-identified and given pseudonyms to protect their identities.

\section{Data analysis}

The research question was examined with others in a previous paper (see Barblett \& Kirk, 2018). Findings showed several key factors were found to support the implementation of the NQS; chief amongst them being distributed leadership. This current paper examines this finding at a deeper level. This analysis of data was approached in much the same way as in the earlier iteration, yet this time hunting for commonalities that may underpin effective leadership. 


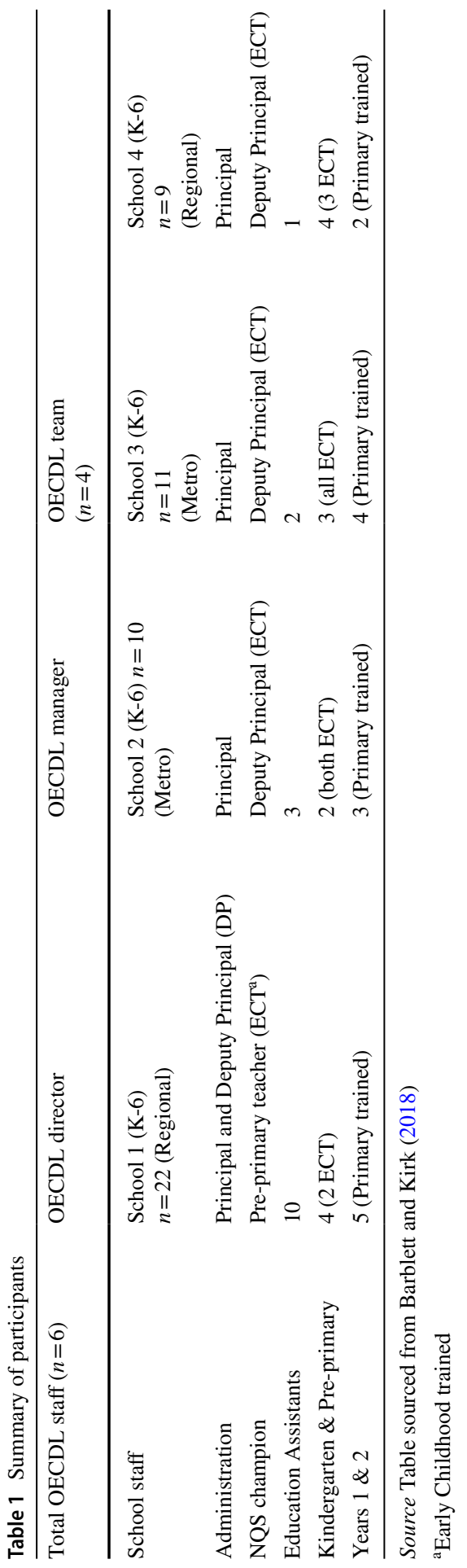


The interview data were transcribed and analysed by both researchers. The data were compared to consider the ways in which each school approached empowering change amongst all staff. Collating common themes and bundling ideas that were present in the interviews identified features enabling leadership within the activity.

\section{Findings and discussion}

AT was used to organise the findings and discussion. In particular, the stages of introducing and implementing the NQS are presented as evolving activity systems. The NQS is the shared object throughout, however, how the activity acts on and with the object changes as a result of the tension(s) experienced. Psychological ownership emerges from the tension and can exist at an individual level and then transmutes to a collective level. In this way, we examined the hierarchical evolution of psychological ownership in the process of implementing the NQS in schools. Hierarchy was not used here to highlight an order of importance, rather it was used to delineate the moving notion of time and the processes that preceded each level before psychological ownership characterised a collective approach to implementing the NQS.

The processes of change explored in this discussion are diagrammatised in the following figure (Fig. 2). Using the AT frame shown in Fig. 1, Fig. 2 highlights the integral feature of psychological ownership, and the key role it takes in supporting leadership (vertical and horizontal) and enduring change. Specifically, the transference of psychological ownership and how it impacts leadership across all levels and features and influences change.

\section{The OECDL professional learning and schools as two contradicting activity systems}

Examining the dissemination of psychological ownership through a hierarchical lens, the first level is represented by the NQS professional learning offered to schools throughout 2015 by the OECDL team. It was at this point the OECDL team transferred psychological ownership of the NQS to principals for the implementation to gain traction within schools.

In interviews, the OECDL team described their journey in rolling out the NQS to schools. They were charged with offering professional development days to school principals and early childhood teachers. They focussed on the reasons to have the NQS, what quality brings, an introduction to the seven Quality Areas of the NQS as well as examining what quality looked like.

However, their initial efforts of delivering the professional learning were met with resistance (tension). Some principals were not convinced they required another regulated process in the school or one that was not the same for all classes and staff, as the NQS only pertained to the early years of school.

When the OECDL staff explored these tensions they realised that the professional learning activity system was centred on showing schools what quality looked 
like according to the NQS (object), without consideration of each school's individual community. Therefore, the examples given may not have described quality or resonated with staff from schools with different school contexts. One staff member rationalised:

... the training we delivered initially was about examples of, "Do you think this is meeting or working towards; based on these criteria? What would you say? Would you say it's meeting or working towards?"

Herein arose the first overt tension between activity systems, where the OECDL professional learning sessions were one activity system, and the school setting was another (Engeström 2001). This activity system is represented in the Fig. 3 below.

As the OECDL had psychological ownership over the importance of the NQS, they were motivated to resolve the tension between the systems. The OECDL team realised they had not acknowledged the principals and teachers as being part of a distinct community (Engeström et al., 2002) and that the resistance was a result of this lack of recognition. Unknowingly, they had inhibited the schools' ability to be self-efficacious, accountable, have a sense of belonging, or identify all elements of psychological ownership needed in the process of adopting the NQS (Avey et al., 2012). In not being given scope for psychological ownership, many principals rejected the proposition of implementing the NQS in their schools. However, things began to change as indicated by the OECDL team member below:

through the journey, and it probably took us at least two years, we shifted our focus from, "What does meeting look like?" to once you've worked out how your school stacks up against the National Quality Standard, and you make some determinations, how do you take that information and integrate it into your whole-school planning.

The OECDL team realised they were telling principals what quality should look like in their schools, when really it should have been the other way around. When

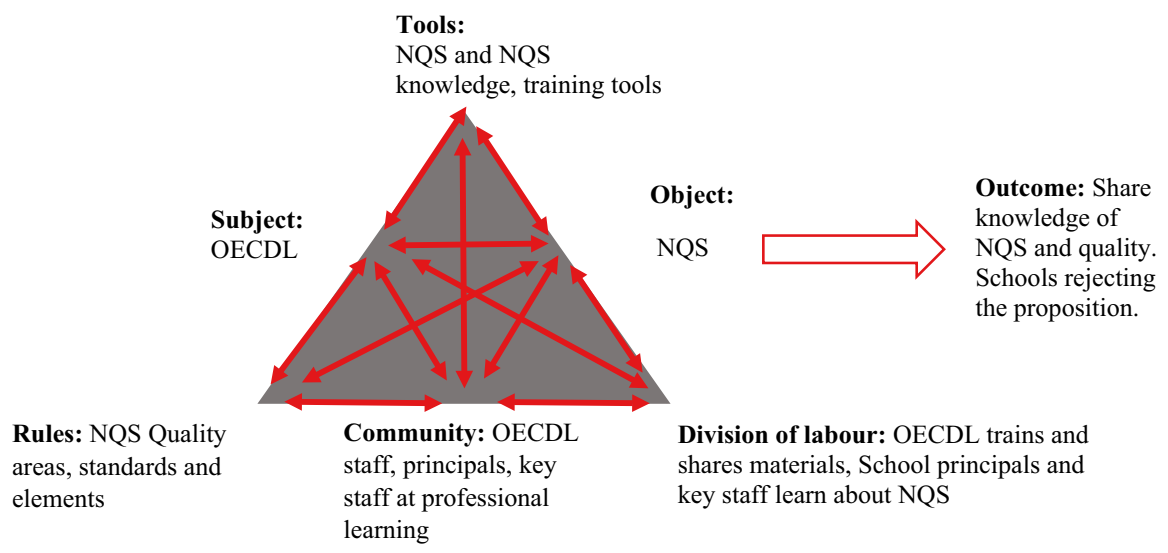

Fig. 3 Activity system 1a) OECDL professional learning school staff in NQS without transference of psychological ownership 
this shift manifested in the workshop content, the principals became more open to the possibility of adopting the NQS tool. Once the principals were on board, they began examining how they could incorporate the NQS into their existing school improvement plans, for example, "amalgamating the quality objectives into their business plans" (Interview School 1 principal). It was with this new reimagining that the principals gained a sense of psychological ownership over the NQS and were more likely to implement it in their respective schools (see Fig. 4).

\section{Principal with psychological ownership}

With the principals' roles centred on influencing others as dual change agents (Connolly et al., 2017) it was necessary for them to see the value of the NQS for their school and gain a sense of psychological ownership. A conviction was necessary as they needed to exert catalytic agency and influence the collective belief (Man \& Farquharson, 2015). One OECD team member said of the leadership role:

...if the leader does use it and understands it (the NQS), they're going to ensure that their staff engage in it, whether or not they want to, and once people engage in it and realise that it is about improvement, and it's about the children .... So, a good leader, and a leader that values best practice, and is there for the right reasons, makes all the difference to a school.

The principals interviewed recognised their role in the implementation of the NQS. School 3 principal commented on the successful implementation by saying, "We were seen to be with the staff, so it gave it a level of importance. So, we have talked about it and we have resourced it. My view is, if we are going to do this, we are going to do this properly". Catalytic agency was exemplified through the principal's overt active participation in the implementation process (McDowall \& Murray, 2012) and demonstrated not only the shared value he placed on the NQS but that

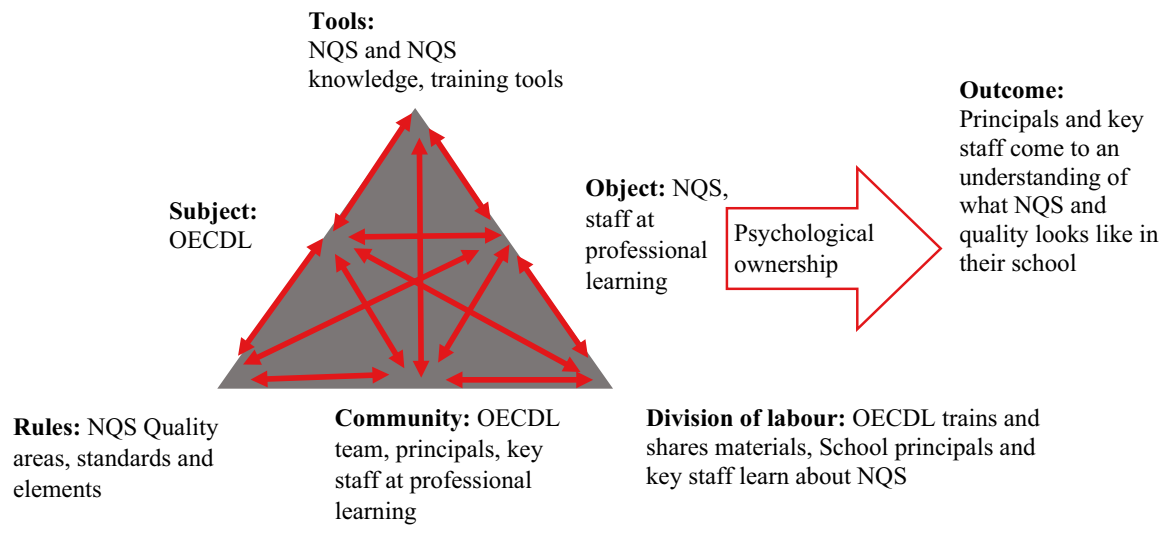

Fig. 4 Activity system 1b) OECDL professional development in NQS for school staff with transference of psychological ownership 
this emergence of distributed leadership also empowered staff to take ownership of the NQS alongside him.

School 3 staff discussed how they deconstructed power relations through distributed leadership and enabled psychological ownership of NQS tools. Specifically, the Deputy Principal (DP) incorporated the NQS supporting materials into staff's performance management. She explained:

I ran the performance management for the EAs using the NQS as a basis. So, they went through and [asked themselves] what are some elements that I need to improve on in my practice. [One EA] took ownership of the outdoor area and planned for what we could put out each day that would provide a variety of different learning styles. So, we had more creative things, and musical things, more mathematical things... So, they all took elements of the NQS to use as a reflective tool.

The DP built staff self-efficacy by empowering the Education Assistants (EAs) to direct their own learning and expertise through using the NQS as a guide. This act also divided the labour (Engeström, 2000a, 2000b) enabling each EA to become accountable for their chosen element and in doing so heightened the quality provision of that facet within the school (Avey et al., 2012).

Growing staff expertise in the Quality Areas was a common approach used by all the participants in gaining staff commitment to the NQS as it provided a solution to the tensions within the activity systems that were presented when staff were confronted with the mandated policy. School 1 principal described how "you set aside time to focus on an area, then you give attention to that, so it was that, I guess, giving itself time". Part of that focus was the allocation of extra time away from teaching and additional resources which made the implementation more palatable for reluctant participants. Through the division of labour and increased self-efficacy and accountability in areas of the NQS, the individual psychological ownership transformed into a collective approach that would support the effectiveness and sustainability of the NQS (Avey et al., 2012; Engeström, 2000a).

Another solution to tensions within the activity system of the school was the introduction of an NQS leader. The principal from School 1 coined it as identifying a 'NQS champion'. The strategy of using an NQS champion who supported staff in implementing the NQS was a common theme across the four schools. These champions were identified for their knowledge of and self-efficacious approach to early childhood education, and their commitment to raising quality in their schools. They were chosen for their potential for transformational leadership (Stamopoulos \& Barblett, 2018) and their existing psychological ownership of quality early childhood education.

While much of the drive behind the NQS fell to the NQS champion, the continued support from the principal was necessary for the implementation to be successful. Where a group (community) feels the outcome is collectively theirs, they build interdependence, and all become accountable to the process of NQS implementation (Pierce \& Jussila, 2010). The principal in School 4 described forming an NQS leadership team and then stepped aside leaving the implementation to those with the expertise. In this school, the NQS champion admitted the initial 
enthusiastic adoption of the tool eventually waned. This was evident through the analysis of staff planning and evaluation documents as there were different levels of take up and sustained effort by teachers. It is possible that when the principal removed their visible support, a fracture occurred in the community impacting the collective psychological ownership and thus the self-efficacy, accountability, and belonging regarding the NQS were harder to sustain. In particular, the relational interdependence described by McDowall and Murray (2012) became unravelled as the mutual dependence that it was built upon was compromised.

\section{Activity system with the inclusion of an NQS champion}

The NQS champion in each of the schools was an early childhood trained staff member. In three of the schools this person was also the DP, however, in School 1 it was an early years' teacher. All champions were mentioned by staff as inspiring, sharing their expertise in early childhood education and described as driving the continuing implementation of the NQS. The champions instilled staff psychological ownership as they suggested different ways of engaging, implementing and documenting the NQS. Two of the champions (Schools 1 and 2) used implementation strategies like games to engage staff in the NQS process such as a Scavenger hunt, and making an iPad movie. Regarding the latter, a small group were given one Quality Area and they had to make a movie on the iPad to convince everyone else that theirs was the most important Quality Area. Games to learn the NQS and how it looks in each school were in response to the tension that was evident within the activity system (Engeström, 2001). Some staff were described as showing minimal interest in the NQS, so these NQS champions responded by electing a fun approach to alleviate the mundane and engage otherwise reluctant participants. The unifying impact of the NQS champion is shown in Fig. 5.

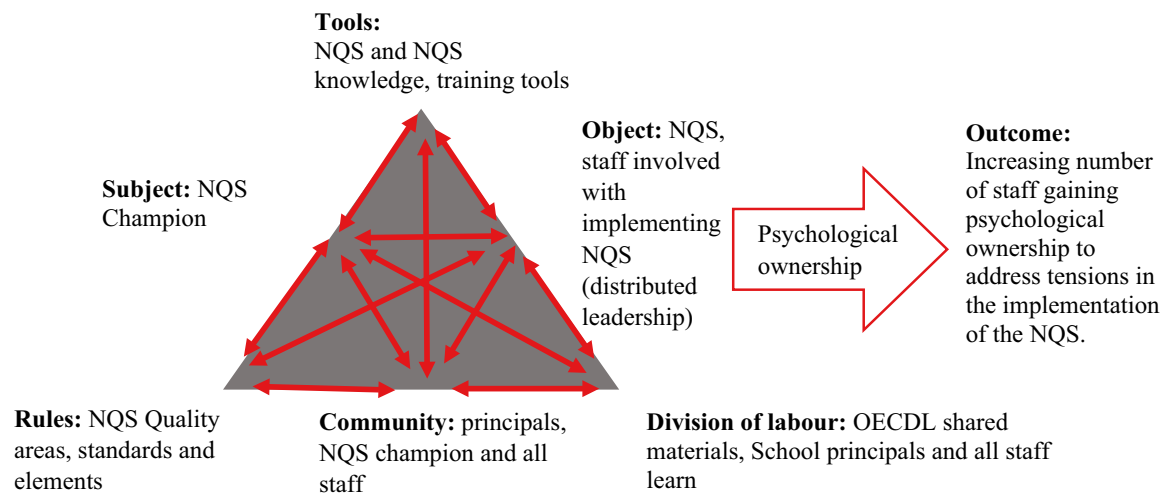

Fig. 5 Activity system as school with NQS champion 


\section{Staff acquiring psychological leadership}

As new tensions arose in the evolving activity systems, solutions and change occurred. The staff gained catalytic agency through inclusion, voice, education, time, and respect for different ways of acquiring psychological ownership. While the NQS champions were instrumental in this stage, it would not have been possible without the preceding actions that occurred in the historical NQS context and the former acts of adopting psychological ownership.

Inclusion occurred when all staff were considered in the process of change. This tended to occur over time and sometimes by accident. For example, the School 2 champion wanted to find more about Quality Area 2 Children's Health and Safety (ACECQA, 2020) and asked the head cleaner a question. The response she received highlighted the wealth of knowledge held by this staff member. The School 2 champion said she,

interviewed the gardeners and cleaners and asked them about the policies that they used and procedures they had adopted... [From this initial discussion the head cleaner] now informs the school of areas that are looking tired and are in need of rejuvenation and the gardeners are now involved in a rostered gardening group and involved a lot more in other areas that have something to do with gardens.

Because of this involvement and collective ownership, the School 2 NQS champion stated there was pedagogical growth within the school as they began to listen to the expertise of ancillary staff who spoke of being "heard" for the first time.

Like the ancillary staff, the EAs also felt they now had a voice through the NQS. Before the NQS, their role was centred on preparing activities and helping in packing them away, however, the NQS gave them a chance to offer their opinions. Specifically, Quality Area 7 highlights that effective leadership promotes a professional learning community (ACECQA, 2020). With this chance to engage, the ten EAs interviewed in School 1 were brimming with ideas about changing pedagogical practices and approaches, revelling in the new world that had given them a voice. It was evident that many EAs interviewed had psychological ownership of the NQS. One EA explained "Yes, we are more included and our opinions-some still see us a bit differently. On the overall we are seen to be a little bit more important." With increased opportunities to discuss student learning, the confidence and self-efficacy grew, which was evident in another EA's comment, "I think the sharing of ideas... like we've been around a long time we've done certain activities a lot of the time, we can say to the teacher, 'this worked best when we did it like this', or whatever, and that is usually taken on board".

Some early childhood teachers believed their voice had been amplified by the adoption of the NQS. They spoke of competing tensions between upper primary and early childhood priorities in school policy formation. The School 4 Kindergarten teacher explained that she felt it gave her a voice but believed this was because the leadership team in her current school recognised the value of the document.

Finally, time and respect for different ways of acquiring psychological ownership need to be realised in this process of change. For example, the Year 2 teacher in 
School 1 shared how it took him time to resolve tensions between how he had been taught to teach and how he thought the NQS was asking him to teach. He grappled with how play-based learning would look for children in Year 2 while still meeting curriculum standards. His school gave him time to visit other schools, learn more and try out new ideas in his practice. It was evident at this school the leaders were aware that psychological ownership takes time as it is an internalisation of sorts, where all facets of the new outcome need to be reassessed and reconfigured as one's own (Avey et al., 2012). The leadership team in School 1 likened their view of change as a 'ripple effect' and knew their staff would need time, so they continued staff discussion and learning about the NQS without trying to force their psychological ownership onto others. Once the Year 2 teacher found his ownership, he became a leader in his own right. With the catalytic agency he gained through ownership, he extended elements of the NQS to reach other areas and years of the school (McDowall \& Murray, 2012). For example, in realisation of Quality Areas 1 and 3, he had an old shipping container that sat in the school's playground painted to look like an auditorium. At lunch times he would place a basket of props nearby. He said he thought it would attract the younger children, but to his surprise it was the Year 6 students who consistently frequented the stage.

\section{School as community: psychological ownership as a collective responsibility}

All staff in interviews described their role in creating quality programs for children, the overriding aim of the NQS. When the school staff came together to implement the NQS, they had a shared aim of quality improvement and became a community in its truest sense. They remained distinct from other communities but unified by a desire and the activity to improve practice (Engeström et al., 2002). To get to this stage of community, a majority of staff members needed to gain ownership of the NQS tool with the desire to improve practice. When a sense of psychological ownership was gained, catalytic agency occurred, further deepening and strengthening the collective view of school improvement.

\section{Limitations}

Some limitations to this study were noted. First, this study used a sample of convenience as these schools were known to be using the NQS and were representative of both metropolitan and regional schools. However, the ways that they had implemented the NQS were unknown until investigated. In addition, the small sample size of four schools can hinder the generalisability of this study. Second, in one of the schools, the NQS team leader was present at most individual and focus group interviews. While the observations made supported what the participants reported, it needs to be noted that it is possible they did not speak as freely as they would have, had their comments been entirely anonymous. 


\section{Conclusion}

This paper has argued that the successful implementation of the NQS is facilitated through distributed leadership. Distributed leadership as a flattened structure (not top-down) enables psychological ownership, and in turn, psychological ownership empowers enduring change. Engeström's third generation Activity Theory has enabled us to articulate how the motivation for resolving tensions during different phases of implementation is derived from and through psychological ownership, and with this impetus organisational change takes place. Once psychological ownership occurred in this study, a momentum gathered, moving the majority of staff's actions toward implementing the NQS. However, where collective leadership was fractured by a leader stepping away, the community's momentum to sustain change was impeded.

This study has implications at both the Department of Education and school levels. Importantly, for the implementation of mandated reforms such as the NQS, schools need to be recognised as a community that is distinct from other communities and through this recognition be enabled ownership. Managing successful change of a mandated policy in schools required psychological ownership at different levels. The change in the four schools described in this paper embodied the leadership constructs of catalytic agency for many staff who previously had no voice, reflective integrity and relational interdependence (McDowall \& Murray, 2012) to build a school community centred on school improvement.

Funding This study was funded by the Department of Education Western Australia (Grant No. 2016-2018).

\section{Declarations}

Ethical approval Ethics were approved by Edith Cowan University (Approval 13935) and the Department of Education.

Open Access This article is licensed under a Creative Commons Attribution 4.0 International License, which permits use, sharing, adaptation, distribution and reproduction in any medium or format, as long as you give appropriate credit to the original author(s) and the source, provide a link to the Creative Commons licence, and indicate if changes were made. The images or other third party material in this article are included in the article's Creative Commons licence, unless indicated otherwise in a credit line to the material. If material is not included in the article's Creative Commons licence and your intended use is not permitted by statutory regulation or exceeds the permitted use, you will need to obtain permission directly from the copyright holder. To view a copy of this licence, visit http://creativecommons.org/licen ses/by/4.0/.

\section{References}

Allen, N., Grigsby, B., \& Peters, M. L. (2015). Does leadership matter? Examining the relationship among transformational leadership, school climate, and student achievement. NCPEA International Journal of Educational Leadership Preparation, 10(2), 1-22. 
Alok, K. (2014). Authentic leadership and psychological ownership: Investigation of interrelations. Leadership and Organization Development Journal, 35(4), 266-285. https://doi.org/10.1108/ LODJ-06-2012-0080.

Australian Children's Education and Care Quality Authority. (2020). National Quality Standard. https:// www.acecqa.gov.au/nqf/national-quality-standard.

Australian Public Service Commission. (2018). Authentic leadership. https://www.apsc.gov.au/authenticleadership.

Avey, J. B., Wernsing, T. S., \& Palanski, M. E. (2012). Exploring the process of ethical leadership: The mediating role of employee voice and psychological ownership. Journal of Business Ethics, 107, 21-34. https://doi.org/10.1007/s10551-012-1298-2.

Barblett, L., \& Kirk, G. (2018). 'National quality standard' in schools: Leadership enabling power and agency. Australasian Journal of Early Childhood, 43(3), 43-51. https://doi.org/10.23965/AJEC. 43.3.05

Bass, B., \& Riggio, R. (2006). Transformational leadership. Taylor and Francis.

Connolly, M., James, C., \& Fertig, M. (2017). The difference between educational management and educational leadership and the importance of educational responsibility. Educational Management Administration and Leadership, 47(4), 504-519. https://doi.org/10.1177/1741143217745880.

Day, C., Sammons, P., Leithwood, K., Harris, A., \& Hopkins, D. (2009). The impact of leadership on pupil outcomes: Final report. DCSF.

Engeström, Y. (1987). Learning by expanding: An activity-theoretical approach to developmental research. Orienta-Konsultit.

Engeström, Y. (1999). Activity theory and individual and social transformation. In Y. Engeström, R. Miettinen, \& R. Punamäki (Eds.), Perspectives on activity theory (pp. 19-37). Cambridge University Press.

Engeström, Y. (2000a). Activity theory as a framework for analysing and redesigning work. Ergonomics, 43(7), 960-974. https://doi.org/10.1080/001401300409143.

Engeström, Y. (2000b). Comment on Blackler et al. Activity theory and the social construction of knowledge: A story of four umpires. Organization, 7(2), 301-302.

Engeström, Y. (2001). Expansive Learning at Work: Toward an activity theoretical reconceptualization. Journal of Education and Work, 14(1), 133-156.

Engeström, Y., Engeström, R., \& Suntio, A. (2002). Can a school community learn to master its own future? An activity-theoretical study of expansive learning among middle school teachers. In G. Wells \& G. Claxton (Eds.), Learning for life in the 21st century: Sociocultural perspectives on the future of education (pp. 211-224). Blackwell Publishing Ltd.

Fullan, M. (2014). The principal: Three keys to maximizing impact. Wiley.

Gronn, P. (2000). Distributed properties: A new architecture for leadership. Educational Management and Administration, 28(3), 317-338.

Hall, G. E., \& Hord, S. M. (2006). Implementing change: Patterns, principles, and potholes. Allyn and Bacon.

Harris, A. (2003). Teacher leadership as distributed leadership: Heresy, fantasy or possibility? School Leadership \& Management, 23(3), 313-324. https://doi.org/10.1080/1363243032000112801.

Harris, A. (2013). Distributed leadership: Friend or foe? Educational Management Administration \& Leadership, 41(5), 545-554. https://doi.org/10.1177/1741143213497635.

Harris, A., \& Hargreaves, A. (2013). Schools performing beyond expectations. Routledge.

Heck, R., \& Hallinger, P. (2010). Testing a longitudinal model of distributed leadership effects on school improvement. Leadership Quarterly, 21, 867-885.

Hennessey, B., Moran, S., Altringer, B., \& Amabile, T. M. (2015). Extrinsic and intrinsic motivation. Wiley Encyclopedia of Management. https://doi.org/10.1002/9781118785317.weom110098.

Man, T. W. Y., \& Farquharson, M. (2015). Psychological ownership in team-based entrepreneurship education activities. International Journal of Entrepreneurial Behavior and Research, 21(4), 600-621. https://doi.org/10.1108/1JEBR-11-2012-0126.

McDowall, C. R., \& Murray, J. (2012). Reconceptualising leadership in the early years. Open University Press.

Minister for Education and Training. (1999). School Education Act. Author.

Park, C. H., Song, J. H., \& Kim, W. (2013). A missing link: psychological ownership as a mediator between transformational leadership and organizational citizenship behaviour. Human Resource Development International, 16(5), 558-574. https://doi.org/10.1080/13678868.2013.839510. 
Pierce, J. L., \& Jussila, I. (2010). Collective psychological ownership within the work and organizational context: Construct introduction and elaboration. Journal of Organizational Behavior, 31(6), 810 834. https://doi.org/10.1002/job.628.

Roth, W. (2004). Introduction: "Activity theory and education: An introduction." Mind, Culture and Activity, 11(1), 1-8. https://doi.org/10.1207/s15327884mca1101_1.

Stamopoulos, E., \& Barblett, L. (2018). Early childhood leadership in action: Evidence based approaches to practice. New York, NY: Routledge.

Wellington, J. (2015). Educational research: Contemporary issues and practical approaches (2nd ed.). Bloomsbury Academic.

Yip, J., Clegg, T., Ahn, J., Bonsignore, E., Gubbels, M., Rhodes, E., \& Lewittes, B. (2014). The role of identity development within tensions in ownership of science learning. In J. L. Polman, E. A. Kyza, D. K. O'Neill, I. Tabak, W. R. Penuel, A. S. Jurow, K. O'Connor, T. Lee, \& L. D'Amico (Eds.), Learning and becoming in practice: The international conference of the learning sciences (ICLS) (Vol. 1, pp. 174-181). International Society of the Learning Sciences.

Publisher's Note Springer Nature remains neutral with regard to jurisdictional claims in published maps and institutional affiliations.

Gillian Kirk is a member of Early Childhood Australia (ECA) and a lecturer and researcher in the School of Education at Edith Cowan University. Her research interests are student engagement, motivation, early childhood education, leadership, retention at university and teacher and student interactions.

Lennie Barblett is a long time member of Early Childhood Australia (ECA) and a current Board member of the Western Australia School Curriculum and Standards Authority. Her research interests include Early childhood education and pedagogy, Early childhood leadership, Learning through play, Partnering with families and communities and Embedding Aboriginal and Torres Strait Islander perspectives in early childhood. 